\title{
Review
}

\section{Cerebral function in diabetes mellitus}

\author{
G.J. Biessels ${ }^{1}$, A.C. Kappelle ${ }^{1}$, B. Bravenboer ${ }^{2}$, D.W. Erkelens ${ }^{3}$, W. H. Gispen ${ }^{1}$ \\ ${ }^{1}$ Department of Medical Pharmacology, Rudolf Magnus Institute, University of Utrecht, The Netherlands \\ ${ }^{2}$ Division of Internal Medicine, Catharina Hospital, Eindhoven, The Netherlands \\ ${ }^{3}$ Department of Internal Medicine, Academic Hospital, Utrecht, The Netherlands
}

\begin{abstract}
Summary Diabetes mellitus is a common metabolic disorder associated with chronic complications such as nephropathy, angiopathy, retinopathy and peripheral neuropathy. Diabetes is not often considered to have deleterious effects on the brain. However, long-term diabetes results in a variety of subtle cerebral disorders, which occur more frequently than is commonly believed. Diabetic cerebral disorders have been demonstrated at a neurochemical, electrophysiological, structural and cognitive level; however, the pathogenesis is still not clear. Probably alterations in cerebral blood supply and metabolic de-
\end{abstract}

rangements play a role, as they do in the pathogenesis of diabetic neuropathy. Furthermore, the brain is also affected by recurrent episodes of hypoglycaemia and poor metabolic control. We describe herein the cerebral manifestations of diabetes and discuss the putative pathogenetic mechanisms. [Diabetologia (1994) 37: 643-650]

Key words Diabetes mellitus, complications, brain, cerebral dysfunction, cognitive dysfunction, pathogenesis, cerebral blood flow, hypoglycaemia, hyperglycaemia, review.
Diabetes mellitus is one of the most common serious metabolic disorders in man. Clinically, it is not one but rather a group of related diseases characterised by chronic hyperglycaemia. Diabetes care and research focus on adequate glycaemic control and on the prevention and treatment of diabetic complications. These complications result from a complex interplay between direct and indirect metabolic consequences of insulin deficiency and additional genetic and environmental factors [1-2]. Major long-term complications are nephropathy, retinopathy, angiopathy and neuropathy. Diabetic neuropathy can involve almost any peripheral nerve and is a major cause of morbidity among diabetic patients [3-5].

Compared to complications in the peripheral nervous system, the diabetic complications in the central

Corresponding author: Professor W.H.Gispen, Department of Medical Pharmacology, Rudolf Magnus Institute, University of Utrecht, Vondellaan 6, NL-3521 GD Utrecht, The Netherlands

Abbreviations: EEG, Electroencephalogram; CBF, cerebral blood flow; NMDA, N-methyl-D-aspartate. nervous system are relatively subtle. Manifestations of diabetic cerebral disorders have been demonstrated at a neurochemical, electrophysiological, structural and neurobehavioural level [6-7]. Unfortunately, only a few studies have combined measures of neurochemical, electrophysiological, structural and cognitive changes [8-13]. In the first part of this review we describe, and provide some links between, the various cerebral manifestations of diabetes.

Various processes may lead to acute cerebral disorders in diabetic patients. Firstly, diabetic subjects have been shown to be at increased risk of cerebrovascular accidents [7, 14-15] with a worse outcome [16]. Secondly, hyper- and hypoglycaemic episodes result in acute cerebral dysfunction [17-20]. The present paper will focus on the gradually developing cerebral disorders in diabetes.

These disorders ensue from the subtle vascular, metabolic and endocrine derangements associated with diabetes. Possibly the same factors responsible for the development of peripheral neuropathy are also involved in diabetic "encephalopathy", i.e. decreased blood flow and hyperglycaemia-induced metabolic de- 
rangements [21-22]. In the second part of this review changes in blood supply and metabolism in the brain will be discussed as putative pathogenetic factors in diabetic cerebral disorders.

\section{The cerebral manifestations in diabetes}

\section{Neurochemical changes}

Animal studies. Most of our knowledge of neurochemical changes in the diabetic brain is based on results obtained with rodent models. Chemically-induced diabetes in the rat resulting from injection of either streptozotocin or alloxan, is the most frequently used animal model.

Acetylcholine release and synthesis in the striatum of streptozotocin-induced diabetic rats is decreased, although the steady-state concentration of acetylcholine is unaltered [23], which cannot be attributed to the amount of choline available. An altered acetylcholine metabolism may contribute to the cognitive deficits exhibited in diabetes.

An increased noradrenaline content, which can be decreased by insulin administration, has been demonstrated in various regions of the diabetic rat brain [2426]. The major noradrenaline metabolite 3-methoxy-4hydroxyphenyl-glycosulphate is decreased indicating that diabetes decreases regional noradrenergic transmission. Chu et al. [8] suggested that the decreased adrenaline and noradrenaline content of the hypothalamus of streptozotocin-diabetic rats is involved in the observed thermoregulatory deficits as both the altered monoamine content and the impaired thermoregulation can be reversed by insulin therapy.

Serotonin turnover is decreased, as evidenced by decreased levels of the serotonin metabolite 5-hydroxyindoleacetic acid in several brain regions in diabetic rats [25-27]. A decreased serotonin turnover in the hypothalamus may represent compensation for the disrupted control of feeding behaviour caused by lack of circulating insulin [25].

Dopaminergic neuronal activity is decreased and dopamine content is increased in the diabetic brain $[8$, 25-27]. Furthermore, changes in dopamine receptors in the striatum of diabetic rats have been reported. The D1-receptor density in the striatum is decreased [28], however, D2-receptor density is increased [29] which is considered to represent a compensatory adjustment to the reduction in central dopaminergic neuronal activity. Another putative explanation is that altered D1and D2-receptor densities are related to G protein function. Activation of D1- and D2-receptors is known to involve $G_{s}$ and $G_{i}$ proteins, respectively. As $G_{i}$ protein function is impaired in the striatum of diabetic rats [30] the altered receptor densities could represent a compensatory mechanism for alterations in $\mathrm{G}$ protein function [28].
Human studies. An increased serotonin turnover has been demonstrated in the brain and cerebrospinal fluid of diabetic patients in severe ketoacidosis [31]. Since ketoacidosis itself may lead to neurochemical alterations quite beyond the effects routinely found in diabetes, these data should be interpreted with caution. Lackovic et al. [26] demonstrated an increased serotonin content in the medial and lateral hypothalamus in post-mortem brain samples from diabetic patients. The dopamine content was increased in the medial hypothalamus, putamen, and medial and lateral parts of the pallidus. None of the patients in this study had a record of neurological, psychiatric, or endocrine disease. Therefore, the observed neurochemical alterations were attributed to diabetes.

In summary, neurochemical alterations in the brain are evident in both human and experimental diabetes. An altered monoaminergic function may increase the risk for development of, for instance, major affective disorders [9, 32-34]. Short-term insulin withdrawal readily induces neurochemical changes in the brain, and insulin replacement leads to complete or partial restoration of these alterations. A possible consequence of exogenously administered insulin would be alternating extremes of monoamine turnover: a reduction during hyperglycaemia and an increase during hypoglycaemia [27].

The relevance of the neurochemical findings in chronically hyperglycaemic rodent models can be questioned, since virtually all diabetic patients are treated with either insulin or oral hypoglycaemic drugs [31]. Other rodent models of diabetes, such as the insulin-dependent spontaneous diabetic BB/Wor rat, could provide valuable new insights into cerebral function in diabetes.

\section{Electrophysiological abnormalities}

Animal studies. BB/Wor rats demonstrate progressive prolongation of visual evoked potential latencies after 6 and 12 months of diabetes [35-36]. These electrophysiological abnormalities could, partly, be due to the accompanying axonal atrophy of the optic nerve. Abnormalities of second order neurons and their projections to the visual cortex could also contribute to the impaired impulse propagation. The alterations in the diabetic optic nerve, although more subtle, appear to be similar to those described in peripheral nerves in this animal model which suggests a common underlying pathogenetic mechanism.

Human studies. In elderly NIDDM patients, slowing of the EEG rhythm occurs over the central cortex [10]. These changes could not be reproduced by induction of acute hyperglycaemia in healthy volunteers [10]. Nonspecific EEG abnormalities have been reported in 19 to $76 \%$ of diabetic children in contrast to 10 to $15 \%$ of 
healthy children [11]. Metabolic control, frequent and severe hypoglycaemic attacks, and vascular changes in the retina are correlated with EEG abnormalities. In children with good, insufficient or poor metabolic control, the frequency of EEG abnormalities was $7 \%$, $22 \%$ and $60 \%$, respectively [11].

Brain stem auditory evoked potentials, visual evoked potentials and somatosensory evoked potentials represent non-invasive procedures for monitoring central nervous system involvement in diabetes [3739]. Evoked potentials involve artificial stimulation of sensory pathways in order to reveal disturbances in both central and peripheral conduction. Several studies report abnormalities in short-latency evoked potentials of both central and peripheral origin in both IDDM and NIDDM patients [12, 38, 40-41]. Central conduction velocities are slowed within 2 years after diabetes onset $[12,37]$. These early conduction abnormalities appear to be correlated with the degree of metabolic control [37].

In addition to increased brainstem auditory, visual evoked, and somatosensory evoked potentials latencies an overall increase in the P300 wave latency has been demonstrated in IDDM patients [13]. The P300 wave is a late cortical neurophysiological event associated with cognitive and mnemonic functions in humans [42-43] and is considered to reflect the speed of neuronal events underlying information processing and appears to be strongly associated with attention and short-term memory [42-44]. An increased P300 latency may be a manifestation of significant impairment of higher brain functions in diabetes [13], and could thus provide a link between the electrophysiological and neurobehavioural abnormalities.

\section{Structural changes}

Animal studies. An ultrastructural study of the cortex of diabetic hamsters revealed vascular lesions, mitochondrial abnormalities in neurite processes, axonal degeneration and loss of neurons [45]. This diffuse structural damage in the brain in long-term, experimental diabetes has been confirmed in diabetic rats [46], where mild neuronal degeneration, especially in the brain stem, and astrogliosis were demonstrated by light and electron microscopy. Quantitative studies on changes in the cerebral neocortex of insulin-treated, long-term diabetic rats demonstrated reduction in brain size and, more specifically, reduction in neocortical size associated with a direct loss of neocortical neurons. The finding of neuronal loss suggests that atrophy is at least partially responsible for the reduction of brain size. Furthermore, diabetes disproportionately reduces the density of the neocortical capillary network and causes thickening of capillary basement membranes [47-48] which could contribute to the development of diabetic cerebral disorders.
Human studies. Fibrosis of the meninges, angiopathy, pseudocalcinosis and severe diffuse degeneration of white and grey matter have been described in a neuropathology study of 16 young long-term IDDM patients [49]. It was assumed that the abnormalities observed in the brains of these patients were the result of diabetes and justified the term "diabetic encephalopathy". However, one should consider that the 16 patients selected for this study presented with widespread vascular disease and retinopathy, 14 showed signs or symptoms of nervous disease and 8 had mental disturbances. The existence of diabetic encephalopathy was substantiated recently by the demonstration of abnormal plaques in magnetic resonance-scans in $69 \%$ of a group of diabetic patients [12]; comparable lesions were observed in only $12 \%$ of an age-matched control group. The lesions observed may represent demyelination, an increased water content or gliosis.

\section{Neurobehavioural disorders}

Diabetic patients have been shown to perform worse than control subjects in a wide range of cognitive tests. Problems with memory and learning, problem solving and mental and motor speed have been noted [10, 5056]. In general, diabetic patients show small but detectable reductions in cognitive function more frequently than is commonly assumed. The majority of differences between healthy and diabetic subjects are not likely to be seen for types of motor function that do not involve complex decisions before responding [57]. Therefore, these deficits appear to have a limited effect on routine day-to-day functioning $[52,55]$.

There has been little agreement between studies regarding the specific tasks impaired in diabetic patients, and the magnitude of the impairment [55]. The heterogeneity of the populations involved may be part of the reason: some studies concern children and adolescents, some adults, some IDDM and some NIDDM.

Identification of possible risk factors may make prevention of cognitive disorders in diabetes possible. The difficulties in assessing these risk factors have been reviewed by Ryan [52]. Studies of risk factors for cognitive dysfunction in diabetic children have focused on four variables: age at diabetes onset, disease duration, metabolic control and the number of clinically significant hypoglycaemic episodes. Age at onset is strongly related with IQ scores [58-60]. Children who develop diabetes before 5 years of age learn new information less efficiently and score lower on tasks of general intelligence than their non-diabetic siblings. In children who develop diabetes after 5 years of age no such impairment is seen. The disease duration affects performance in only a small subset of tests; namely, those measuring school achievement and verbal intelligence [59]. Poor performance could be attributed to increased absenteeism from school [52]; however, it has 
been shown that this does not account fully for the cognitive deficits observed in diabetic children [61-62].

Inadequate glycaemic control, as determined by $\mathrm{HbA}_{1}$ values, is related to cerebral dysfunction in children as do severe hypoglycaemic episodes [60]. It has recently been demonstrated that visual and spatial abilities are correlated with even asymptomatic recurrent hypoglycaemia [62].

The correlation between early diabetes onset and cognitive impairment can be explained by two phenomena. Firstly, children who develop diabetes early experience more hypoglycaemic episodes than children who develop it later. This can be attributed to a heightened sensitivity to insulin, a lower dietary compliance and a poorer communication of hypoglycaemic symptoms in young children [60]. Secondly, the brains of young children are very sensitive to the effects of virtually any abnormal metabolic or electrophysiological event making it more likely that severe hypoglycaemic episodes have deleterious effects when they occur early in life [52].

Prevention of diabetic complications has been attributed to intensified insulin treatment. However, this increases the frequency of hypoglycaemia [63-64], and may thus adversely affect the brain. The frequency of severe hypoglycaemic episodes is inversely correlated with IQ and measures of inspection time and reaction time in adult IDDM patients [52, 56, 65-66]. Although a correlation between cognitive function and hypoglycaemic episodes has been repeatedly demonstrated, two recent studies failed to show such an effect $[54,63]$. However, the evidence in favour of a correlation between cognitive function and hypoglycaemia seems convincing.

Poor glycaemic control has been shown to impair cognitive function in NIDDM [52-54, 57]. Subjects with increased $\mathrm{HbA}_{1}$ levels tend to perform more poorly on learning, reasoning and compiex psychomotor tasks. Poor glycaemic control contributes to other longterm diabetic complications such as retinopathy and peripheral neuropathy. It has recently been suggested that the primary predictor of diabetic neurobehavioural dysfunction is the development of other clinically significant diabetic complications [54]. Patients with mild to moderate retinopathy show mild impairment on tests requiring complex problem solving and abstract reasoning skills [67]. Furthermore, definite distal symmetrical neuropathy is associated with a lower level of cognitive performance, particularly on psychomotor tasks. A tentative explanation is that the same pathogenetic mechanisms are involved in central and peripheral neuropathy [53].

We have mentioned that altered monoaminergic function in diabetes may predispose patients to major affective disorders $[9,32-34,68]$. An increased prevalence of psychiatric disorders, in particular depressive and anxiety disorders, has been reported in both IDDM and NIDDM [32-34, 51, 69-70]. The com- posite estimate for the prevalence of active depression in 11 uncontrolled studies (five IDDM, three NIDDM three mixed or non-specified) was $18 \%$ [33]. Although depressive symptoms are more common in the medically ill in general, there appears to be an increased incidence in diabetic patients [32-33]. The reliability and validity of psychiatric diagnoses in the medically ill have been questioned, since some of the criterion symptoms for psychiatric diagnoses are also symptoms of unstable diabetes $[33,71]$. However, Lustman et al. [72] found that exclusion of somatic symptoms from diagnostic criteria had little effect on the observed prevalence of major depression and dysthymic disorder in diabetes.

The significance of clinical depression in diabetes should not be underestimated. Depression is a debilitating disorder that typically impairs all aspects of an individual's functioning $[32-33,51]$. Cognitive deficits and psychiatric disorders could even interfere with treatment compliance and thus impair glycaemic control. The cause of the increased prevalence of depression in diabetes remains unclear. Depression may result from an inability to cope with the stresses of diabetes, but may also result from direct effects of diabetes on the central nervous system, or a combination of both $[33,51,69]$.

\section{Pathogenetic mechanisms}

The manifestations of diabetic cerebral disorders, described earlier in this review, are diverse and several processes play a role in their pathogenesis. The presence of cerebral disorders in both IDDM and NIDDM is intriguing. Factors other than the pathogenetic mechanisms differentiating both types of diabetes appear to play a major role.

Vascular disorders. Thickening of capillary basement membranes, the hallmark of diabetic microangiopathy, has been demonstrated in the brain of diabetic humans and animals [47, 48, 73]. In addition to morphological changes in the cerebral vaculature, alterations in CBF and vascular reactivity have been reported.

Decreased CBF has been described in both acutely and chronically hyperglycaemic animals [74-75]. The relationship between the degree of hyperglycaemia and $\mathrm{CBF}$ is linear and the decrease in CBF shows a regional distribution. The presence of a regional variation in reduction of $\mathrm{CBF}$ suggests that other factors besides systemic effects induced by glucose, such as hyperosmolarity or hyperviscosity, mediate the reduction in flow. Whether a decreased brain capillary density is involved in reduced CBF remains to be determined, since reports on this issue are contradictory $[47$, 76]. A decreased CBF might be implicated in the pathological changes of the diabetic brain, similarly to decreased nerve blood flow in the pathogenesis of periph- 
eral diabetic neuropathy [21]. It is not certain whether good-to-moderate glycaemic control in diabetic patients produces similar alterations in $\mathrm{CBF}$ as it does in animal models. Decreases in basal CBF have been reported in IDDM [7], and changes in CBF correlate inversely with diabetes duration [77]. However, in one study of normoglycaemic IDDM subjects CBF was actually found to be increased, particularly in the cortex. A striking finding was the resemblance of the pattern of regional $\mathrm{CBF}$ in the IDDM patients to that in patients with attention deficit disorders [78].

Cerebrovascular reactivity is impaired in long-term diabetic patients and animals [79-82]. Sympathetic dysfunction (e.g., reduced circulating catecholamines and diminished cerebral $\beta$-adrenoceptor sensitivity) and increased stimulation of the thromboxane $\mathrm{A}_{2}-\mathrm{PGH}_{2}$ receptor have been implicated [81-82]. Cerebral vasoreactivity, and accompanying changes in CBF, during hypoglycaemia, hypotension, hypoxia and hypercapnia are important compensatory mechanisms. A blunting of the cerebral hyperaemic response to hypoglycaemia, leading to functional impairment in the CNS, has been reported in chronically diabetic rats [82]. Therefore, diabetic patients might be at greater risk of hypoglycaemia-induced central nervous system impairments than non-diabetic subjects. Recent evidence suggests that during hypoglycaemia neuropsychological impairment is more pronounced in diabetic than in control subjects with the same blood glucose level [83].

Metabolic disorders. Tight control of blood glucose levels in insulin treated diabetic patients imposes a major risk: overdosage of insulin may result in severe hypoglycaemia which acutely impairs cognitive functioning [19-20, 54, 84-85]. The awareness of hypoglycaemia which is caused by activation of the autonomic nervous system, diminishes with increased duration of diabetes and with strict glycaemic control [19]. Hypoglycaemic episodes themselves may be implicated in the development of this unawareness and associated impairment of the sympathoadrenal response [19-20]. Cognitive changes that accompany a single hypoglycaemic episode are usually considered to be transient because neurobehavioural test performance returns to pre-hypoglycaemic baseline levels with restoration of normoglycaemia [54]. However, repeated episodes of hypoglycaemia have been shown to be a major cause of permanent cognitive impairment $[50,52,56,65-66]$ and may cause cumulative damage to the brain. This process may be analogous to the progressive deterioration of intellectual function which is demonstrable following chronic exposure to various insults such as hypoxia induced by sleep apnoea or trauma from recurrent head injury [66].

In rats, the EEG slows as the blood glucose level falls to the range of $2.0-2.5 \mathrm{mmol} / \mathrm{l}$ [86]. Neuronal necrosis does not ensue until the EEG has been isoelec- tric for at least several minutes, the extent of neuronal necrosis being related to the duration of cerebral isoelectricity [87]. These findings suggest that energy failure and loss of ion homeostatis are associated with cessation of EEG activity, and may trigger the deleterious events leading to neuronal damage [88]. Selective necrosis of neurons during hypoglycaemia, sparing astrocytes and oligodendrocytes, has been shown to result from overactivation of a subtype of excitatory amino acid receptor, the NMDA-receptor. NMDA-receptor overactivation leads to pathologically enhanced levels of free intracellular calcium [89-90], in turn leading to loss of nuclear and mitochondrial function and activation of proteases and other calcium-dependent enzymes [90-92]. The distribution of hypoglycaemiainduced neuronal necrosis within the brain, with early damage in the cerebral cortex, striatum and hippocampus [86], correlates with NMDA-receptor density [93]. NMDA antagonists have been shown to prevent been shown to prevent neuronal necrosis in hypoglycaemia $[88,94]$. The role of excitatory amino acids in hypoglycaemia-induced acute brain damage imposes the possibility of pharmacotherapeutic intervention [95].

The brain handles glucose and other nutrients differently in diabetes [7], and transport of glucose, electrolytes and amino acids into the brain is altered [96-99]. However, reports about brain glucose metabolism are not equivocal. Several studies reported a reduced brain glucose uptake in chronicly hyperglycaemic rats $[7,96$, 100] which has been attributed to diminished concentrations of glucose transporters at the blood-brain barrier [100], although this has not been confirmed by some studies [75-76]. In humans, major changes in glucose uptake across the blood-brain barrier apparently do not occur, except in extreme hypo-or hyperglycaemia [101]. Although glucose uptake is not affected in the brain of diabetic patients, glucose metabolism may be altered and has been reported to be increased [78].

In diabetic patients and animals the ratio of brain to blood glucose concentrations is increased $[18,102$, 103]. This implies that even in normoglycaemia the central nervous system of diabetic subjects is exposed to increased glucose concentrations. Hyperglycaemia-induced metabolic derangements are implicated in the pathogenesis of peripheral diabetic neuropathy [22]. In the peripheral nervous system, hyperglycaemia-induced nerve myo-inositol depletion is thought to reduce Na,K-ATPase activity, leading to nerve dysfunction [1]. Decreased Na,K-ATPase activity has been demonstrated in the central nervous system of streptozotocin-diabetic rats [104] and shows regional variation, with the decrease being most pronounced in the cerebral cortex and hippocampus. However, chronically elevated glucose levels do not appear to reduce the brain myo-inositol content, in fact in diabetes it appears to be increased $[18,97]$. The link between myoinositol depletion and $\mathrm{Na}$, K-ATPase activity in the central nervous system is therefore questionable. 
In summary, central nervous system and peripheral nervous system metabolism are altered differently in diabetes. The role of the cerebral metabolic changes in the pathogenesis of diabetic cerebral disorders remains to be elucidated.

\section{Conclusions and clinical implications}

Long-term diabetes can result in a variety of subtle cerebral disorders which occur more frequently than is commonly believed. Manifestations of these disorders include alterations in neurotransmission, electrophysiological abnormalities, structural changes and neurobehavioural alterations. The effect of cerebral dysfunction on the daily functioning of diabetic patients appears to be limited. Although this is comforting, it should be considered that there is only limited knowledge into the exact magnitude of the impact of diabetes on the brain, especially in the long term. Most diabetic cerebral disorders are not routinely screened for in clinical practice. However, the clinician should be aware of affective disorders occurring in diabetic patients which may interact with diabetes at several levels. Moreover, drug treatment of these disorders may improve both mood and glycaemic control in diabetes.

Clinically, glycaemic control appears to be the most important factor in preventing diabetic cerebral disorders, still it plays a dual role. On the one hand, chronic hyperglycaemia has a long-term deleterious effect on the brain. Cognitive performance deteriorates and cerebral neurochemistry, metabolism and vasculature are altered. Attainment of normoglycaemia could prevent these phenomena. On the other hand, the risks associated with the achievement of near normoglycaemia are considerable. The occurrence of frequent hypoglycaemic episodes is a major risk factor in the development of cognitive impairment in diabetes. The level of glycaemic control which has the lowest impact on the brain in the long term remains to be determined.

In the clinical and experimental approach to diabetes attention must be paid to the effect of diabetes on the central nervous system. Clinical and animal studies are required to increase insight into the magnitude and the pathogenesis of diabetic cerebral disorders.

\section{References}

1. Greene DA, Lattimer SA, Sima AAF (1987) Sorbitol, phosphoinositides, and sodium-potassium-ATPase in the pathogenesis of diabetic complications. N Engl J Med 316: 599-606

2. Strowig S, Raskin P (1992) Glycemic control and diabetic complications. Diabetes Care 15: 1126-1140

3. Brown MJ, Ashbury AK (1984) Diabetic neuropathy. Ann Neurol 15: 2-12

4. Niakan E, Harati Y, Comstock JP (1986) Diabetic autonomic neuropathy. Metabolism 35: 224-234
5. Vinik AI, Holland MT, Le Beau JM, Liuzzi FJ, Stansberry KB, Colen LB (1992) Diabetic neuropathies. Diabetes Care 15: $1926-1975$

6. Mooradian AD (1988) Diabetes and the central nervous system. Endocr Rev 9: 346-356

7. McCall AL (1992) The impact of diabetes on the CNS. Diabetes 41: 557-570

8. Chu PC, Lin MT, Shian LR, Leu SY (1986) Alterations in physiologic functions and brain monoamine content in streptozotocin-diabetic rats. Diabetes 35: 481-485

9. Broderick PA, Jacoby JH (1988) Serotinergic function in diabetic rats: psychotherapeutic implications. Biol Psychiatry 24: 234-239

10. Mooradian AD, Perryman K, Fitten J, Kavonian GD, Morley JE (1988) Cortical function in elderly non-insulin dependent diabetic patients. Behavioral and electrophysiologic studies. Arch Intern Med 148: 2369-2372

11. Haumont D, Dorchy H, Pelc S (1979) EEG abnormalities in diabetic children. Clin Pediatr 18: 750-753

12. Dejgaard A, Gade A, Larsson H, Balle V, Parving A, Parving HH (1991) Evidence for diabetic encephalopathy. Diabetic Med 8: 162-167

13. Pozzessere G, Valle E, De Crignis S et al. (1991) Abnormalities of cognitive functions in IDDM revealed by $\mathrm{P} 300$ event-related potential analysis. Diabetes 40: 952-958

14. Roehmholdt ME, Palumbo PJ, Wishnant JP, Elveback LR (1983) Transient ischemic attack and stroke in a community-based diabetic cohort. Mayo Clin Proc 58: 56-58

15. Abbott RD, Donahue RP, Macmahon SW, Reed DM, Yano K (1987) Diabetes and the risk of stroke. The Honolulu heart program. JAMA 257: 949-952

16. Sutherland GR, Peeling J, Sutherland E et al. (1992) Forebrain ischemia in diabetic and nondiabetic BB rats studied with ${ }^{31} \mathrm{P}$ magnetic resonance spectroscopy. Diabetes 41 : 1328-1334

17. Foster DW (1991) Diabetes mellitus. In: Wilson JD, Braunwald E, Isselbacher KJ et al. (eds) Harrison's principles of internal medicine. 12th edn. McGraw-Hill Inc., New York, pp 1749-1753

18. Kreis R, Ross BD (1992) Cerebral metabolic disturbances in patients with subacute and chronic diabetes mellitus: detection with proton MR spectroscopy. Radiology 184: 123130

19. Heller S, Ward JD (1993) Neurologic consequences of hypoglycemia and pathogenic mechanisms involved in diabetic neuropathy. Curr Opin Neurol Neurosurg 6: 423-428

20. Veneman T, Mitrakou A, Mokan M, Cryer P, Gerich J (1993) Induction of hypoglycemia unawareness by asymptomatic noctural hypoglycemia. Diabetes 42: 1233-1237

21. Low PA, Tuck PR, Takeuchi M (1987) Nerve microenvironment in diabetic neuropathy. In: Dyck PJ, Thomas PK, Asbury AK, Winegard AI, Porte D (eds) Diabetic neuropathy. Saunders, Philadelphia, pp 289-298

22. Greene DA, Lattimer SA (1988) Pathogenesis and prevention of diabetic neuropathy. Diabetes Metab Rev 4:201221

23. Welsh B, Wecker L (1991) Effects of streptozotocin-induced diabetes on acetylcholine metabolism in rat brain Neurochem Res 16: 453-460

24. Trulson ME, Himmel CD (1985) Effects of insulin and streptozotocin-induced diabetes on brain norepinephrine metabolism in rats. J Neurochem 44: 1873-1876

25. Di Giulio AM, Tenconi B, La Croix R et al. (1989) Denervation and hyperinnervation in the nervous system of diabetic animals II: monoaminergic and peptidergic alterations in diabetic encephalopathy. J Neurosci Res 24: $362-$ 368 
26. Lackovic Z, Salkovic M, Kuci Z, Relja M (1990) Effect of long-lasting diabetes mellitus on rat and human brain monoamines. J Neurochem 54: 143-147

27. Bellush LL, Reid SG (1991) Altered behavior and neurochemistry during short-term insulin withdrawal in streptozotocin-induced diabetic rats. Diabetes 40: 217-222

28. Salkovic M, Lackovic Z (1992) Brain D1 dopamine receptor in alloxan-induced diabetes. Diabetes 41:1119-1121

29. Lozovsky D, Saller CF, Kopin IJ (1981) Dopamine receptor binding is increased in diabetic rats. Science 214: 10311033

30. Abbracchio MP, Di Luca M, Di Giulio AM, Cattabeni F, Tenconi B, Gorio A (1989) Denervation and hyperinnervation in the nervous system of diabetic animals III: functional changes of $G$ proteins in diabetic encephalopathy. $J$ Neurosci Res 24: 517-523

31. Rowland NE, Bellush LL (1989) Diabetes mellitus: stress, neurochemistry and behavior. Neurosci Biobehav Rev 13: 199-206

32. Lustman PJ, Griffith LS, Clouse RE, Cryer PE (1986) Psychiatric illness in diabetes mellitus. J Nerv Ment Disease 174: 736-742

33. Lustman PJ, Griffith LS, Gavard JA, Clouse RE (1992) Depression in adults with diabetes. Diabetes Care 15: 16311639

34. Leedom L, Meehan WP, Procci W, Zeidler A (1991) Symptoms of depression in patients with type II diabetes mellitus. Psychosomatics 32: 280-286

35. Sima AAF, Zhang WX, Cherian PV, Chakrabarti S (1992) Impaired visual evoked potential and primary axonopathy in the optic nerve in the diabetic BB/W-rat. Diabetologia 35: $602-607$

36. Kamijo M, Cherian PV, Sima AAF (1993) The preventive effect of aldose reductase inhibition on diabetic optic neuropathy in the BB/W-rat. Diabetologia 36: 893-898

37. Pozzessere G, Rizzo PA, Valle E et al. (1988) Early detection of neurological involvement in IDDM and NIDDM. Multimodal evoked potentials versus metabolic control. Diabetes Care 11: 473-480

38. Martini A, Comacchio F, Magnavita V (1991) Auditory brainstem and middle latency evoked responses in the clinical evaluation of diabetes. Diabet Med 8 [Suppl]: S74S77

39. Nakamura R, Noritake M, Hosoda Y, Kamakura K, Nagata $\mathrm{N}$, Shibasaki H (1992) Somatosensory conduction delay in central and peripheral nervous system of diabetic patients. Diabetes Care 15: 532--535

40. Donald MW, Williams Erdahl DL, Surridge DHC et al. (1984) Functional correlates of reduced central conduction velocity in diabetic subjects. Diabetes 33:627-633

41. Khardori R, Soler NG, Good DC, Devlesc Howard AB, Broughton D, Walbert J (1986) Brainstem auditory and visual evoked potentials in type 1 (insulin-dependent) diabetic patients. Diabetologia 29:362-365

42. Polich J, Howard L, Star A (1983) P300 and digit span. Curr Opin Neurol Neurosurg 6: 423-428

43. Surwillo WW (1984) P300 latency and digit span. Psychophysiology 21: 708-709

44. Hillyard SA, Kutas M (1983) Electrophysiology of cognitive processing. Annu Rev Psychol 34: 33-61

45. Luse SA, Gerritsen GC, Dulin WE (1970) Cerebral abnormalities in diabetes mellitus: an ultrastructural study of the brain in early-onset diabetes mellitus in the Chinese hamster. Diabetologia 6: 192-198

46. Mukai N, Hori S, Pomeroy M (1980) Cerebral lesions in rats with streptozotocin-induced diabetes. Acta Neuropathol (Berl) 51:79-84
47. Jakobsen J, Sidenius P, Gundersen HJG, Osterby R (1987) Quantitative changes of cerebral neocortical structure in insulin-treated long-term streptozotocin-induced diabetes in rats. Diabetes 36:597-601

48. Junker U, Jaggi C, Bestetti G, Rossi GL (1985) Basement membrane of hypothalamus and cortex capillaries from normotensive and spontaneously hypertensive rats with streptozotocin-induced diabetes. Acta Neuropathol (Berl) 65: 202-208

49. Reske-Nielsen E, Lundbaek K, Rafaelsen OJ (1965) Pathological changes in the central and peripheral nervous system of young long-term diabetics. Diabetologia 1: 233-241

50. Bale RN (1973) Brain damage in diabetes mellitus. Br J Psychiatry 122: 337-341

51. Cox DJ, Gonder-Frederick L (1992) Major developments in behavioral diabetes research. J Consult Clin Psychol 60: 628-638

52. Ryan CM (1988) Neurobehavioral complications of type I diabetes. Diabetes Care 11: 86-93

53. Ryan CM, Williams TM, Orchard TJ, Finegold DN (1992) Psychomotor slowing is associated with distal symmetrical polyneuropathy in adults with diabetes mellitus. Diabetes 41: $107-113$

54. Ryan CM, Williams TM, Finegold DN, Orchard TJ (1993) Cognitive dysfunction in adults with type 1 (insulin-dependent) diabetes mellitus of long duration: effects of recurrent hypoglycaemia and other chronic complications. Diabetologia 36: 329-334

55. Richardson JT (1990) Cognitive function in diabetes mellitus. Neurosci Biobehav Rev 14: 385-388

56. Deary IJ, Crawford JR, Hepburn DA, Langan SJ, Blackmore LM, Frier BM (1993) Severe hypoglycaemia and intelligence in adult patients with insulin-treated diabetes. Diabetes 42: 341-344

57. Reaven GM, Thompson LW, Nahum D, Haskins E (1990) Relationship between hyperglycaemia and cognitive function in older NIDDM patients. Diabetes Care 13: 16-21

58. Ack M, Miller I, Weil WB (1961) Intelligence of children with diabetes mellitus. Pediatrics 28: 764-770

59. Ryan CM, Vega A, Drash A (1985) Cognitive deficits in adolescents who developed diabetes early in life. Pediatrics 75: 921-927

60. Rovet JF, Ehrlich RM, Hoppe M (1987) Intellectual deficits associated with early onset of insulin dependent diabetes mellitus in children. Diabetes Care 10:510-515

61. Fowler MG, Johnson MP, Atkinson SS (1985) School achievement and absence in children with chronic health conditions. J Pediatr 106: 683-687

62. Golden MP, Ingersoll GM, Brack CJ, Russel BA, Wright JC, Huberty TJ (1989) Longitudinal relationship of asymptomatic hypoglycemia to cognitive function in IDDM. Diabetes Care 12: 89-93

63. Reichard P, Berglund A, Britz A, Levander S, Rosenqvist U (1991) Hypoglycaemic episodes during intensified insulin treatment: increased frequency but no effect on cognitive function. J Intern Med 229: 9-16

64. DCCT Research Group (1991) Epidemiology of severe hypoglycemia in the diabetes control and complications trial. Am J Med 90: 450-459

65. Wredling R, Levander S, Adamson U, Lins PE (1990) Permanent neuropsychological impairment after recurrent episodes of severe hypoglycaemia in man. Diabetologia 33: $152-157$

66. Langan SJ, Deary IJ, Hepburn DA, Frier BM (1991) Cumulative cognitive impairment following recurrent severe hypoglycaemia in adult patients with insulin-treated diabetes mellitus. Diabetologia 34: 337-344 
67. Rennick PM, Wider RM, Sargent J, Ashley BJ (1968) Retinopathy as an indicator of cognitive-perceptual-motor impairment in diabetic adults (Summary). Proc 76th Annu Conv AM Psychol Assoc: 473-474

68. Popkin MK, Callies AL, Lentz RD, Colon EA, Sutherland DE (1988) Prevalence of major depression, simple phobia, and other psychiatric disorders in patients with long-standing type I diabetes mellitus. Arch Gen Psychiatry 45: 64-68

69. Surridge DHC, Williams Erdahl DL, Lawson JS et al. (1984) Psychiatric aspects of diabetes mellitus. Br J Psychiat 145:269-276

70. Gavard JA, Lustman PJ, Clouse RE (1993) Prevalence of depression in adults with diabetes. Diabetes Care 16: 11671178

71. Rodin G, Voshart K (1986) Depression in the medically ill: an overview. Am J Psychiatry 143: 696-705

72. Lustman PJ, Harper GW, Griffith LS, Clouse RE (1986) Use of the diagnostic interview schedule in patients with diabetes mellitus. J Nerv Ment Disease 174: 743-746

73. Johnson PC, Brendel K, Meezan E (1982) Thickened cerebral cortical capillary basement membranes in diabetics. Arch Pathol Lab Med 106: 214-217

74. Duckrow RB, Beard DC, Brennan RW (1987) Regional cerebral blood flow decreases during chronic and acute hyperglycemia. Stroke 18: 52-58

75. Harik SI, LaManna JC (1988) Vascular perfusion and blood-brain glucose transport in acute and chronic hyperglycemia. J Neurochem 51: 1924-1929

76. Kikano GE, LaManna JC, Harik SI (1989) Brain perfusion in acute and chronic hyperglycemia in rats. Stroke 20: 10271031

77. Rodriguez G, Nobili F, Celestino MA et al. (1993) Regional cerebral blood flow and cerebrovascular reactivity in IDDM. Diabetes Care 16:462-468

78. Grill V, Gutniak M, Björkman O et al. (1990) Cerebral blood flow and substrate utilization in insulin-treated diabetic subjects. Am J Physiol 258: E813-E820

79. Kastrup J, Rorsgaard S, Parving HH, Lassen NA (1986) Impaired autoregulation of cerebral blood flow in long-term type I (insulin-dependent) diabetic patients with nephropathy and neuropathy. Clin Physiol 6: 549-559

80. Albert SG, Gomez CR, Russeli S, Chaitman BR, Bernbaum M, Kong BA (1993) Cerebral and ophthalmic artery hemodynamic responses in diabetes mellitus. Diabetes Care 16: $476-482$

81. Mayhan WG, Simmons LK, Sharpe GM (1991) Mechanism of impaired response of cerebral arterioles during diabetes mellitus. Am J Physiol 260: H319-H326

82. Pelligrino DA, Albrecht RF (1991) Chronic hyperglycemic diabetes in the rat is associated with a selective impairment of cerebral vasodilatory responses. J Cereb Blood Flow Metab 11: 667-677

83. Wirsén A, Tallroth G, Lindgren M, Agarhd CD (1992) Neuropsychological performance differs betweeen type I diabetic and normal men during insulin-induced hypoglycaemia. Diabetic Med 9: 156-165

84. Hoffman RG, Speelman DJ, Hinnen DA, Conley KL, Guthrie RA, Knapp RK (1989) Changes in cortical functioning with acute hypoglycaemia and hyperglycemia in type I diabetes. Diabetes Care 12:193-197

85. Blackman JD, Towle VL, Lewis GF, Spire JP, Polonsky KS (1990) Hypoglycemic thresholds for cognitive dysfunction in humans. Diabetes 39: 828-835
86. Auer RN (1986) Progress review: hypoglycemic brain damage. Stroke 17:699-708

87. Auer RN, Olsson Y, Siesjö BK (1984) Hypoglycemic brain injury in the rat. Correlation of density of brain damage with the EEG isoelectric time: a quantative study. Diabetes 33: 1090-1098

88. Wieloch T (1985) Hypoglycaemia-induced neuronal damage prevented by an $\mathrm{N}$-methyl-D-aspartate antagonist. Science 230: 681-683

89. Choi DW (1988) Glutamate neurotoxicity and diseases of the nervous system. Neuron 1: 623-634

90. Siesjö BK, Bengtsson F (1989) Calcium fluxes, calcium antagonists, and calcium-related pathology in brain ischemia hypoglycaemia and spreading depression: a unifying hypothesis. J Cerb Blood Flow Metab 9: 127-140

91. Araki N, Greenberg JH, Sladky JT, Uematsu D, Karp A, Reivich M (1992) The effect of hyperglycemia on intracellular calcium in stroke. J Cereb Blood Flow Metab 12: 469 476

92. Meldrum B, Garthwaite J (1990) Excitatory amino acid neurotoxicity and neurodegenerative disease. Trends Parmacol Sci 11: 379-387

93. Young AB, Fagg GE (1990) Excitatory amino acid receptors in the brain: membrane binding and receptor autoradiographic approaches. Trends Pharmacol Sci 11: 126133

94. Papagapiou MP, Auer RN (1990) Regional neuroprotective effects of the NMDA receptor antagonist MK-801 (Dizocilpine) in hypoglycemic brain damage. J Cereb Blood Flow Metab 10:270-276

95. Pizzi M, Ribola M, Valerio A, Memo M, Spano PF (1991) Various $\mathrm{Ca}^{2+}$ entry blockers prevent glutamate-induced neurotoxicity. Eur J Pharmacol 209: 169-173

96. Mooradian AD, Morin AM (1991) Brain uptake of glucose in diabetes mellitus: the role of glucose transporters. Am J Med Sci 301: 173-177

97. Knudsen GM, Jakobsen J, Barry DI, Compton AM, Tomlinson DR (1989) Myo-inositol normalizes decreased sodium permeability of the blood-brain barrier in streptozotocin diabetes. Neuroscience 29:773-777

98. Crandall EA, Fernstrom JD (1983) Effect of experimental diabetes on the levels of aromatic and branched-chain amino acids in rat blood and brain. Diabetes 32: 222-230

99. Trachtman H, Futterweit S, Sturman JA (1992) Cerebral taurine transport is increased during streptozotocin-induced diabetes in rats. Diabetes 41: 1130-1140

100. Pardridge WM, Triguero D, Farrell CR (1990) Downregulation of blood-brain barrier glucose transporter in experimental diabetes. Diabetes 39: 1040-1044

101. Gutniak M, Blomqvist G, Widén L, Stone-Elander S, Hamberger B, Grill V (1990) D-[U- ${ }^{11}$ C]glucose uptake and metabolism in the brain of insulin-treated diabetic subjects. Am J Physiol 258: E805-E812

102. Bruhn H, Michaelis T, Merboldt KD, Hänicke W, Gyngell ML, Frahm J (1991) Monitoring cerebral glucose in diabetics by proton MRS. Lancet 337: 745-746

103. Hofer RE, Lanier WL (1991) Effects of insulin on blood, plasma, and brain glucose in hyperglycemic diabetic rats. Stroke 22: 505-509

104. Leong SF, Leung TKC (1991) Diabetes induced by streptozotocin causes reduced Na-K ATPase in the brain. Neurochem Res 16: 1161-1165 